\title{
Transcriptional analysis of the gene encoding peptidyl-tRNA hydrolase in Escherichia coli
}

\author{
L. Rogelio Cruz-Vera, José Manuel Galindo and Gabriel Guarneros
}

Author for correspondence: Gabriel Guarneros. Tel: + 52555747 3338. Fax: + 525557477100 . e-mail: guarnero@lambda.gene.cinvestav.mx

Departamento de Genética y Biología Molecular, Centro de Investigación y de Estudios Avanzados del IPN, Apartado Postal 14-740, México DF 07000, Mexico

\begin{abstract}
Gene pth encodes peptidyl-tRNA hydrolase (Pth), an enzyme that cleaves peptidyl-tRNAs released abortively from ribosomes during protein synthesis. In the Escherichia coli chromosome, pth is flanked by ychH and ychF, two genes of unknown function. Pth is essential for cell viability, especially under conditions leading to overproduction of peptidyl-tRNA. In an attempt to unveil the elements that affect $p$ th expression, the transcriptional features of the pth region were investigated. Northern blot experiments showed that both pth and ychF, the 3'-proximal gene, are cotranscribed in a bicistronic transcript. However, transcripts containing each of the individual messages were also detected. Accordingly, two transcriptional promoters were identified by primer extension experiments: one located upstream of pth, which presumably gives rise to both the mono and bicistronic pth transcripts, and the other, preceding ychF, which generates its monocistronic message. Deletion analysis indicates that pth transcript stability depends on ychF integrity. Also, a defect in RNase E activity resulted in Pth overproduction. It is proposed that RNase E processing within ychF in the bicistronic message limits pth expression.
\end{abstract}

Keywords: bicistronic mRNA, mRNA stability, $p t h, y c h F$, RNase E

\section{INTRODUCTION}

Peptidyl-tRNA hydrolase (Pth; EC 3.1.1.29) cleaves peptidyl-tRNAs prematurely released from ribosomes during protein synthesis (Atherly \& Menninger, 1972). Pth activity is required to recycle tRNA into cell metabolism, a function essential for Escherichia coli viability (Atherly \& Menninger, 1972; García-Villegas et al., 1991; Schmitt et al., 1997). The enzyme is encoded in $p t h$, a gene located at $26 \mathrm{~min}$ in the E. coli chromosome. The nucleotide sequence of $p t h$ has been determined and the predicted $21 \mathrm{kDa}$ polypeptide identified and purified (Cruz-Vera et al., 2000; Galindo et al., 1994; García-Villegas et al., 1991). The three-dimensional structure of crystalline Pth has been solved, and, using site-directed mutagenesis, the active and receptor sites for the substrate have been identified on the molecule (Fromant et al., 1999; Schmitt et al., 1997). A temperature-sensitive mutant (Atherly \& Menninger, 1972) harbours a mutation, named $p t h(T s)$, which determines an unstable Pth protein (Cruz-Vera et al., 2000). Upon shift-up to non-permissive temperatures,

Abbreviations: Pnp, polynucleotide phosphorylase; Pth, peptidyl-tRNA hydrolase. the mutant accumulates peptidyl-tRNAs, protein synthesis is arrested and cells die due to tRNA starvation. Another mutant affected in $p t h$, termed $p t h(\mathrm{rap})$, was selected as non-permissive for phage $\lambda$ vegetative growth (García-Villegas et al., 1991). Phage mutants able to grow on $p t h$ (rap) bacteria are affected in minigenes located in loci termed bar (Guzmán \& Guarneros, 1989). The bar minigenes are sequences which encode two-amino-acid peptides (Ontiveros et al., 1997); however, bar mRNA is defective in translation termination, releasing peptidyl-tRNA at a high frequency instead of the free peptide (Dinçbas et al., 1999; Hernández et al., 1997; Hernández-Sánchez et al., 1998; HeurguéHamard et al., 1998, 2000). Thus, phage growth may be impaired by starvation for specific tRNA due to sequestration as peptidyl-tRNA. Recent results suggest that high-level expression of non-functional proteins inhibits the growth of bacteria defective in Pth activity. The cause of the inhibition may be sequestration of specific tRNA, cognate to the last sense codon of overproduced proteins (Menez et al., 2000). This result may imply that Pth could be central to an alternative translationtermination activity.

E. coli pth has been the paradigm for a group of homologous ORF sequences conserved in eubacteria 


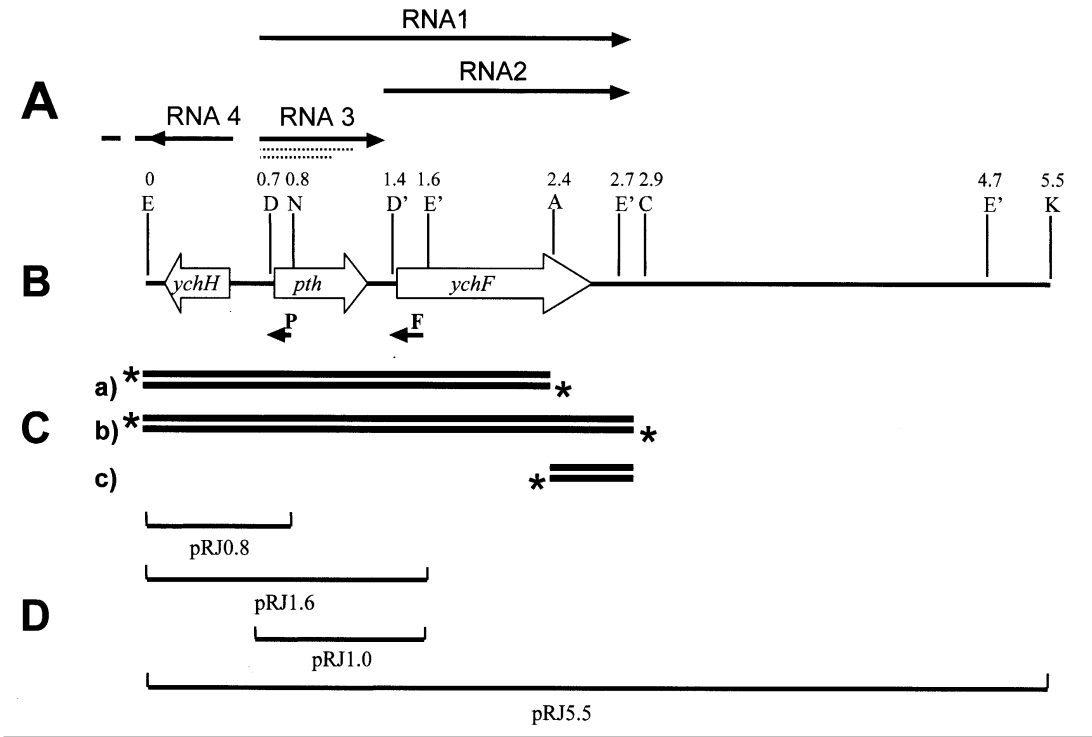

Fig. 1. Map of the genetic region around pth, showing probes and cloned regions. (A) Arrows showing the origin, size and direction of the transcripts described here. The dotted lines under the RNA3 arrow represent transcripts with a common 5 '-end but variable $3^{\prime}$-ends (see Fig. 2, lane 1). The discontinuous line after the RNA4 arrow indicates that the transcript continues, for an undetermined distance, beyond the EcoRI site (see Discussion). (B) Genetic and physical map of the $5.5 \mathrm{~kb}$ EcoRI-Kpnl chromosome segment containing pth. Open arrows represent size, relative position and direction of the respective ORFs. The position and distances, in kb from the EcoRI end, of some restriction sites are marked above the diagram: A, ApaLI; D, Ddel; D', Dral; C, Clal; E, EcoRI; E', EcoRV; K, Kpnl; N, Nrul. (C) Position, size and direction (represented by leftward arrows labelled $\mathbf{P}$ and $\mathbf{F}$ ) of the RNA probes used in Northern blot assays. The heavy parallel lines represent the location and extension of the DNA probes used in S1 protection assays. Probes were $\left[{ }^{32} \mathrm{P}\right]$ phosphate labelled (asterisks) at both $5^{\prime}$-ends, $\mathbf{a}$ and $\mathbf{b}$; or at the ychF-proximal 3'-end, c. (D) Lengths and positions of the DNA segments cloned in the plasmid constructs used.

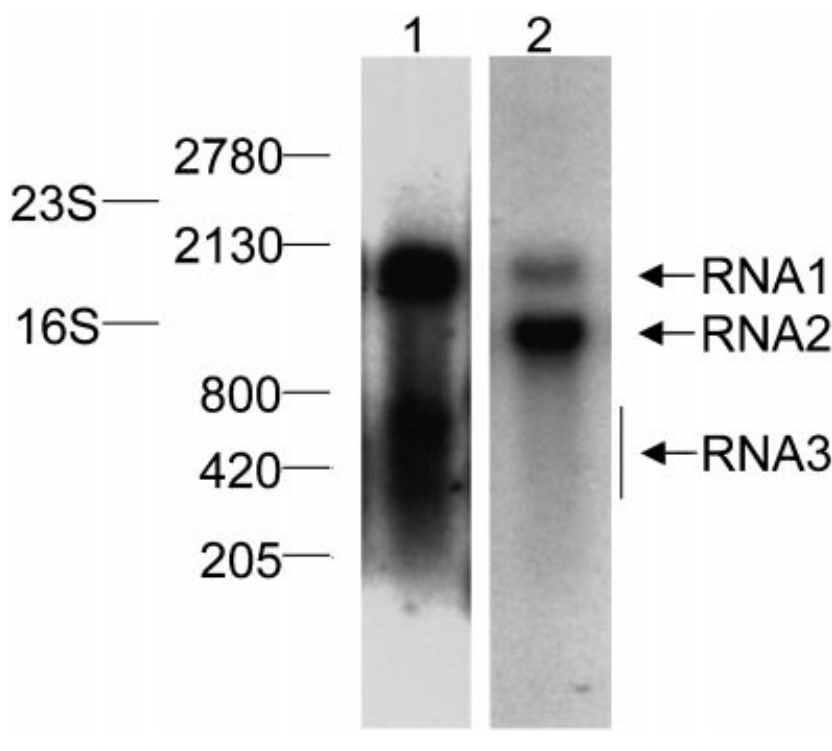

Fig. 2. Transcripts containing pth and $y c h F$ sequences. Northern blot assay of the transcripts isolated from strain C600 transformed with pRJ5.5. The specific transcripts of different sizes (arrows) were revealed by labelled RNA probes $\mathbf{P}$ (lane 1) or $\mathbf{F}$ (lane 2) (see Fig. 1). The numbers on the left indicate the size, in $\mathrm{nt}$, and migration position of the in vitro-synthesized markers (see Methods). The band positions of the rRNAs (23S and 16S) were visualized with ethidium bromide. The difference in band RNA1 intensities between lanes 1 and 2 was due to the different film exposure times to the blotted membrane. Lane 1 was overexposed to visualize the smeared RNA signal between 800 and 200 nt. and eukaryotes (De La Vega et al., 1996; Schmitt et al., 1997). In the E. coli chromosome, $p$ th is flanked by genes of unknown function: $y c h F$ (named gtp 1 in Galindo et al., 1994) located $3^{\prime}$ to $p t h$, and $y c h H$ on the $5^{\prime}$ end (orf2 in Galindo et al., 1994). A polypeptide encoded by $y c h H$ has not been shown, but $y c h F$ encodes a homologue to a conserved GTP-binding protein (Gtp1 in Galindo et al., 1994). As the concentration of Pth in the cell is critical to prevent peptidyl-tRNA-mediated lethality, we aimed to understand how pth expression is controlled. Our evidence indicates that both $5^{\prime}$ and $3^{\prime}$ sequences flanking $p t h$ affect the concentration of $p t h$ transcripts and Pth expression. However, except for limiting endonuclease RNaseE activity, Pth concentration is highly stable to changes in the growth conditions of the wild-type and of various mutant strains.

\section{METHODS}

Strains and plasmids. The strains of Escherichia coli K-12 used were $\mathrm{C} 600$ ( $\mathrm{F}^{-}$hsdR thr-1 leu-6 thi-1 supE44 tonA lacY1, our collection) and C600ams1. This latter strain was obtained by $\mathrm{P} 1_{\mathrm{vir}}$ cotransduction of ams 1 with $z c t 229:: \operatorname{Tn} 10$. The donor strain was IBPC642 (Hajnsdorf et al., 1994). Bacteria were grown at $32^{\circ} \mathrm{C}$ in Luria-Bertani (LB) or LB mediumampicillin $\left(100 \mu \mathrm{g} \mathrm{ml}^{-1}\right)$.

Plasmid constructs. pRJ5.5 was constructed by cloning the EcoRI $(27 \cdot 1 \mathrm{~min})-K p n \mathrm{I}(27 \mathrm{~min})$ chromosomal segment in clone (246) 12A3(-) of Kohara (Kohara et al., 1987; Rudd, 1992) into the EcoRI and KpnI sites of vector pGEM-4 (Promega), a vector convenient to obtain RNA probes through in vitro transcription using T7 RNA polymerase. Construct pRJ1.6 was obtained by subcloning the EcoRI-EcoRV $1.6 \mathrm{~kb}$ segment from plasmid pRJ5.5 into the EcoRI and SmaI sites of pGEM-4. pRJ1.0 was obtained through cloning, into the 
A

ATGAGCACGTTACCGAGTAACGAAGCGTTTTTGCGTTT

$\underline{\text { CATATGTCACCTCCGGAACTTTCTGGGTTGTAACAGGG }}$

AATACCCCTCTTCCTTATGTGTAAAGTATAGACAACACC

$-10$ $-35$ CAGTGGGTTATGTGCGGGCGTGATCACAATTACAACCCT

TATTTCAACAAAACTTTACAAATAAACGCCTGAACACC

TTGACTTTCTAATAGTCCACTCAGGCAATTATTACGTT ATCTGCATTTGATACGCAGTTTTTITGTCAAGCGGGGCC GCAACCAGTAAACTACGCGCCAGTTATGTACACACTC $-10 \quad+1$ AGGACAAAAAAACGTGACGATTAAATTGATTGTCGGCC SD pth start
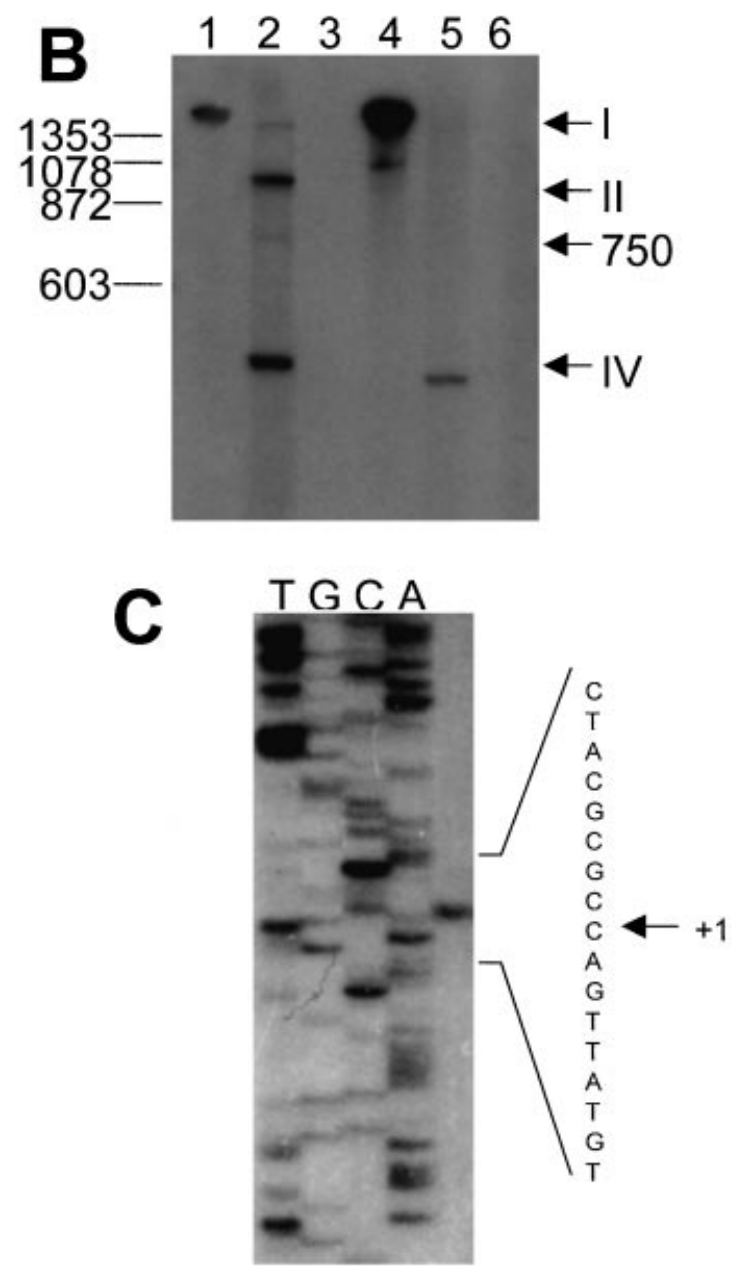

Fig. 3. Characterization of the 5 -ends of pth and $y c h H$ transcripts. (A) Sequence of the intergenic region between $y c h H$ and pth showing, underlined, the putative transcriptional promoters (-35 and -10) for $y c h H$, and for pth (Ppth), appropriately oriented relative to the Shine-Dalgarno (SD) regions and translation starts (also underlined). $\triangle$, Site limiting the DNA insert containing pth in pRJ1.0. (B) RNA preparation from strain $\mathrm{C} 600$ transformed with pRJ5.5 hybridized to
EcoRI and SmaI sites of pGEM-4, of a PCR fragment containing $p t h$ and short flanking segments amplified from the pRJ5.5 template. The primers used were 5'-TACGTTATCTGAATTCGATACGCAGTTT-3', a sequence located upstream from the putative $p t h$ promoter (Dutka et al., 1993) modified to contain an EcoRI site (underlined), and 5'GAATTTGTCGATATCGCCGGTCTGG-3', harbouring the EcoRV site (underlined) located within $y c h F$ (Fig. 1B, coordinate $1 \cdot 6$ ). pR J0.8 was created by subcloning the $0.8 \mathrm{~kb}$ EcoRI-NruI fragment (Fig. 1B, coordinates 0 and $0 \cdot 8$, respectively) into the EcoRI and SmaI sites in pGEM4.

RNA preparation and Northern blotting. Total RNA was extracted with hot phenol from a $10 \mathrm{ml}$ culture at $65^{\circ} \mathrm{C}$, as described by Aiba et al. (1981). About $30 \mu \mathrm{g}$ of RNA was denatured in $40 \%$ formamide, $5 \mu \mathrm{g} \mathrm{ml}^{-1}$ ethidium bromide solution at $65^{\circ} \mathrm{C}$ for $10 \mathrm{~min}$. The RNA species were resolved by electrophoresis through $1.5 \%$ denaturing agarose gel containing $2 \cdot 2 \mathrm{M}$ formaldehyde and transferred to a nylon membrane (Hybond-N, Amersham Pharmacia Biotech) as recommended by the manufacturer (Manson \& Williams, 1985). Hybridization was carried out at $55^{\circ} \mathrm{C}$ in $5 \times$ SSPE [0.9 $\mathrm{M} \mathrm{NaCl}, 0.05 \mathrm{M}$ sodium phosphate and 0.004 M EDTA $(\mathrm{pH} 7 \cdot 7)$ ], $0.5 \%$ SDS, $100 \mu \mathrm{g} \mathrm{ml}^{-1}$ salmon sperm DNA, $5 \times$ Denhardt's solution $[0 \cdot 1 \%$ bovine serum albumin BSA, $0 \cdot 1 \%$ Ficoll and $0 \cdot 1 \%$ polyvinyl pyrrolidone]. Formamide $(40 \%)$ was added to hybridization reactions using RNA probes. After $16 \mathrm{~h}$ incubation, membranes were rinsed twice at $55^{\circ} \mathrm{C}$ with $2 \times$ SSPE, $0 \cdot 1 \%$ SDS, once at $65{ }^{\circ} \mathrm{C}$ with $1 \times$ SSPE, $0 \cdot 1 \%$ SDS and finally once at $65^{\circ} \mathrm{C}$ with $0.1 \times$ SSPE, $0.1 \%$ SDS. The dried membrane was exposed to X-ray film for at least $24 \mathrm{~h}$.

RNA probes for Northern blotting were synthesized by in vitro transcription and labelled with $\left[\alpha_{-}^{32} \mathrm{P}\right] \mathrm{UTP}$ (see below). For probe $\mathbf{P}$, used in Figs 2 and 5B (upper panel), the template was pR J0.8 restricted with DdeI (Fig. 1B), whereas for probe F (Fig. 2) the template was pRJ1.6 restricted with DraI (Fig. 1C). The in vitro transcription mixtures contained, in $20 \mu \mathrm{l}$ : $40 \mathrm{mM}$ Tris/HCl (pH 8.0); $10 \mathrm{mM} \mathrm{MgCl}_{2} ; 5 \mathrm{mM}$ DTT; $50 \mathrm{mM} \mathrm{KCl} ; 300 \mu \mathrm{M}$ of three NTPs; $10 \mu \mathrm{Ci}\left[\alpha_{-}{ }^{32} \mathrm{P}\right] \mathrm{UTP}$ (3000 Ci mmol ${ }^{-1}, 111 \mathrm{TBq} \mathrm{mmol}^{-1}$; Amersham Pharmacia Biotech); 50 mg BSA ml ${ }^{-1}$; 10 units RNasin (Promega); $2 \mu \mathrm{g}$ template DNA; and 5 units T7 RNA polymerase (New England BioLabs). They were incubated for $30 \mathrm{~min}$ at $37^{\circ} \mathrm{C}$. The reaction was stopped with 10 units RNase-free DNase (Boehringer Mannheim, Germany) for $15 \mathrm{~min}$ at $37^{\circ} \mathrm{C}$. Finally, $2 \mu$ lof $0.5 \mathrm{MEDTA}, 80 \mu \mathrm{l} 3 \mathrm{M}$ sodium acetate $(\mathrm{pH} 5 \cdot 2)$

labelled DNA probes (Fig. 1C) and resolved by electrophoresis through a denaturing polyacrylamide gel (see Methods). Untreated self-hybridized probes: probe $\mathbf{a}$, lane 1 ; probe $\mathbf{b}$, lane 4. RNA hybridized and S1-digested with probe a, lane 2; with probe $\mathbf{b}$, lane 5 . S1-digestion controls of the probes $\mathbf{a}$ and b mock-hybridized to yeast tRNA, lanes 3 and 6, respectively. Arrows mark the electrophoretic migration distances of the protected fragments I-IV. The different migration, of about $20 \mathrm{bp}$, of fragment IV in lanes 2 and 5 may be due to limited degradation of probe $\mathbf{b}$ during in vitro labelling. The numbers on the left-hand side of the autoradiogram are the sizes, in $\mathrm{nt}$, of a set of marker fragments (see Methods). (C) Primer extension assay on the pth transcripts (rightmost lane) and DNA sequencing ladder of the region. RNAs obtained from strain C600 transformed with pRJ5.5 DNA were used as reversetranscription templates. The primer was a designed oligonucleotide, complementary to the sense strand of an internal region in the pth ORF (see Methods). The signal in the primer extension lane corresponds to a cytidine (arrow +1 ) between the -10 box and the SD sequences (A). 


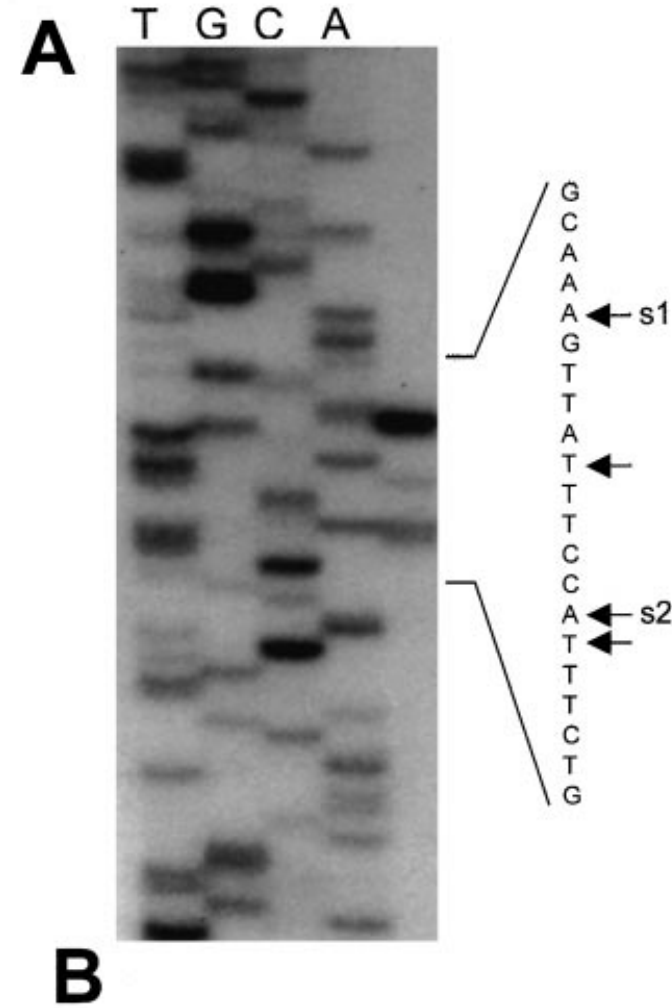

AGCAACGAACCGATTGCACGCCTTTAAA

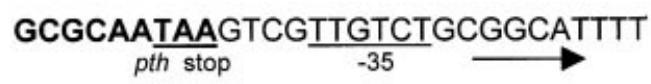

TGCCGAGTGCCGTGTATAATAGGCAAAGT

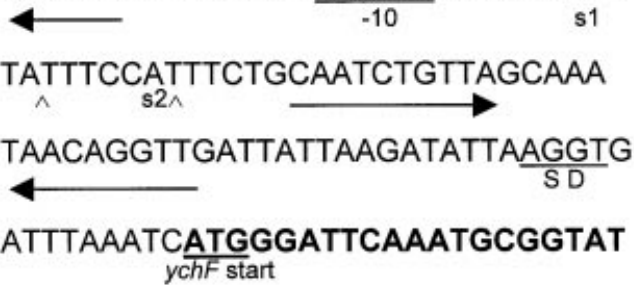

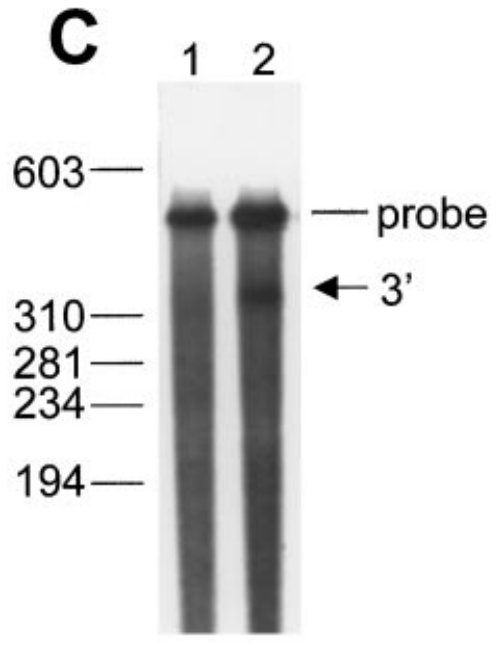

D

AAAGATGGCGATGTGATGAACTTCCTTTTCAACGTC

TAATTAATTTATTGTCTCATGAGGTTTCGCTAAATCTCA ychF stop

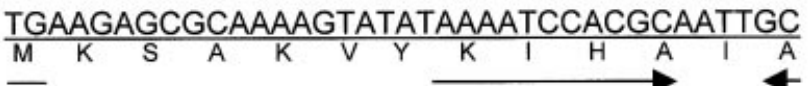

GTGGATTTTTCATTTCACCGAGTCCTAATCATTCTTGT

W

AACATCCTACACTTTTGTGCTTATTGCCTATAGTGAAC

CACGAGAATAATTAAAGACATAAGTGTTCAGATGCCG

GATATCTCATTAGCAGTGATATACGTAAGTTTTTGTAG

Fig. 4. The $5^{\prime}$ - and $3^{\prime}$-ends of the $y c h F$ transcripts. (A) Primer extension assay on the $y c h F$ transcripts (rightmost lane) and sequencing ladder of the corresponding DNA region. On the right-hand edge of the panel are the interpreted nucleotide sequence of the region and four identified signals corresponding to two adenines and two thymidines (arrows). The adenines marked s1 and s2 correspond with in vitro transcriptional starts (see text). (B) Nucleotide sequence of the $p t h-y c h F$ intergenic region. The -35 and -10 regions of the putative transcriptional promoter and SD region for $y c h F$ are underlined, and inverted repeats are underlined by convergent pairs of arrows. $\wedge$, Thymines identified in (A). (C) S1 endonuclease protection analysis as in Fig. 3(B) but using 3'-labelled probe c (Fig. 1C); lane 1, mock hybridization with yeast tRNA, showing a signal of the self-hybridized probe; lane 2, hybridization with RNA from the C600-pRJ5.5 transformant. (D) DNA sequence of the 3'-region beyond ychF showing, underlined, two short ORFs and the oneletter code for the amino acids encoded above. The convergent arrows indicate complementary inverted repeats. The $3^{\prime}-$ end of the $y c h F$ transcript is located close before the underlined EcoRV site.

and $10 \mu \mathrm{g}$ glycogen (Boehringer Mannheim) were added. The stopped reactions were phenol/chloroform $(1: 1 ; \mathrm{v} / \mathrm{v})$ extracted, precipitated with $2.5 \mathrm{vols}$ ethanol at $-20^{\circ} \mathrm{C}$ for at least $20 \mathrm{~min}$ and finally resuspended in $10 \mu \mathrm{l}$ water. For hybridization, the RNA probe was denatured with $40 \%$ formamide at $65^{\circ} \mathrm{C}$ for $10 \mathrm{~min}$ and used as indicated above. The specific activity of the probes used was about $3 \times$ $10^{6}$ c.p.m. $\mathrm{ng}^{-1}$.

The RNA size markers used in Fig. 2 were obtained by T7-
RNA polymerase run-off transcription of pRJ0.8 DNA template linearized with DdeI (205 nt), NciI, (420 nt), EcoRI (800 nt) and PvuII (2780 nt); and pRJ1.6 DNA template linearized with $B g l \mathrm{I}(2130 \mathrm{nt})$.

The DNA probe for $\beta$-lactamase (bla) transcripts (Fig. 5, lower panel) was obtained by PCR amplification on a pGEM4 template. Thirty femtomoles of DNA template was added to the amplification mixture [in $50 \mu \mathrm{l} ; 40 \mathrm{mM}$ Tris $/ \mathrm{HCl}(\mathrm{pH} 8 \cdot 0)$, $5 \mathrm{mM} \mathrm{MgCl}_{2}, 10 \mathrm{mM}$ DTT, $50 \mathrm{mM} \mathrm{NaCl}, 150 \mu \mathrm{M} 3 \mathrm{dNTPs}$, 
$50 \mu \mathrm{Ci} \quad\left[\alpha^{-}{ }^{32} \mathrm{P}\right] \mathrm{dCTP} \quad\left(6000 \mathrm{Ci} \mathrm{mmol}^{-1}, \quad 222 \mathrm{TBq} \mathrm{mmol}^{-1}\right.$; Amersham Pharmacia Biotech), 1 unit Taq DNA polymerase (Applied Biosystems) and $10 \mathrm{pmol}$ of primers]. The primers were 5'-GTATTCAACATTTCCGTG-3', beginning within the second codon of bla, and 5'-CAATGCTTAATCAGTGAG-3' complementary to the final bla ORF sequence. Amplification was carried out for 50 cycles $\left(95^{\circ} \mathrm{C}, 30 \mathrm{~s} ; 55^{\circ} \mathrm{C}\right.$, $30 \mathrm{~s} ; 72^{\circ} \mathrm{C}, 1 \mathrm{~min}$ ) after an initial denaturation period of $1 \mathrm{~min}$ at $95^{\circ} \mathrm{C}$. The amplified product was denatured at $95^{\circ} \mathrm{C}$ and added to the hybridization mixture described above.

S1 nuclease analysis. For $\mathrm{S} 1$ endonuclease protection analysis, the DNA probes (Fig. 1C, a and b) and $\phi$ X184 DNA (Fig. 3B, markers) were labelled at the $5^{\prime}$-ends by the phosphate exchange reaction. Ten picomoles of DNA was dissolved in the exchange mixture [in $20 \mu \mathrm{l} ; 40 \mathrm{mM}$ Tris/ $\mathrm{HCl}(\mathrm{pH} 8.0)$, $10 \mathrm{mM} \mathrm{MgCl}_{2}, 5 \mathrm{mM}$ DTT, $50 \mathrm{mM} \mathrm{NaCl}, 50 \mu \mathrm{Ci}\left[\gamma^{32}{ }^{32} \mathrm{P}\right] \mathrm{ATP}$ (3000 Ci mmol ${ }^{-1}$, $111 \mathrm{TBq} \mathrm{mmol}^{-1}$; Amersham Pharmacia Biotech) and 10 units T4 polynucleotide kinase (New England Biolabs) ] and incubated at $37^{\circ} \mathrm{C}$ for $30 \mathrm{~min}$. The reaction was stopped at $65^{\circ} \mathrm{C}$ for $10 \mathrm{~min}$ and extracted with phenol/ $\mathrm{CHCl}_{3}$. The solution was precipitated with $2 \mu \mathrm{l} 3 \mathrm{M}$ sodium acetate $(\mathrm{pH} \mathrm{5 \cdot 2)}$ and cold ethanol. Probe c (Fig. 1C) was labelled by 3 -repair at the ApaLI site; $10 \mathrm{pmol}$ of the DNA fragment was dissolved in the repair mixture [in $20 \mu \mathrm{l}: 40 \mathrm{mM}$ Tris/ $\mathrm{HCl}$ (pH 8.0), $10 \mathrm{mM} \mathrm{MgCl}, 5 \mathrm{mM}$ DTT, $50 \mathrm{mM} \mathrm{KCl}$, $50 \mathrm{mg} \mathrm{ml}^{-1} \mathrm{BSA}, 600 \mu \mathrm{M}$ of dNTPs except dCTP, $10 \mu \mathrm{Ci}[\alpha-$ $\left.{ }^{32} \mathrm{P}\right] \mathrm{dCTP}$ (6000 $\mathrm{Ci} \mathrm{mmol}^{-1}$, Amersham Pharmacia Biotech) and 10 units DNA polymerase Klenow fragment (New England Biolabs)]. The mixture was incubated at $37^{\circ} \mathrm{C}$ for $30 \mathrm{~min}$. Finally, the labelled probe $\mathrm{c}$ was extracted, precipitated and redissolved in water as described for probes $\mathbf{a}$ and $\mathbf{b}$.

For the S1 endonuclease protection assays in Figs 3(B) and 4(C), $3 \mu \mathrm{g}$ (about $10^{6}$ c.p.m.) of labelled DNA was hybridized [in $30 \mu \mathrm{l} ; 80 \%$ formamide, $0.4 \mathrm{M} \mathrm{NaCl}, 40 \mathrm{mM}$ PIPES, $1 \mathrm{mM}$ EDTA (pH 6.4)] to $15 \mu \mathrm{g}$ of total cell RNA, or of yeast tRNA as a control. The mixture was incubated for $10 \mathrm{~min}$ at $90^{\circ} \mathrm{C}$, cooled to $55^{\circ} \mathrm{C}$ and maintained at this temperature for $8 \mathrm{~h}$. Then, the samples were digested with S1 nuclease (200 units, Boehringer Mannheim) in $300 \mu \mathrm{l}$ of $50 \mathrm{mM}$ acetate buffer (pH 4.5), $280 \mathrm{mM} \mathrm{NaCl}$ and $4.5 \mathrm{nM} \mathrm{ZnSO}$ (Régnier \& Portier, 1986). After $2 \mathrm{~h}$ incubation at $37^{\circ} \mathrm{C}$, the reaction mixture was added to $80 \mu \mathrm{l}$ stop solution [4 $\mathrm{M}$ ammonium acetate, $50 \mathrm{mM}$ EDTA $(\mathrm{pH} \mathrm{8.0)}$ and $50 \mu \mathrm{g}$ yeast tRNA (Boehringer Mannheim)] and precipitated with ethanol. The pellets were rinsed with ethanol $(75 \%)$, dried and redissolved in loading buffer $(80 \%$ formamide, $0 \cdot 1 \%$ bromophenol blue, $0 \cdot 1 \%$ xylene cyanol and $2 \mathrm{mM}$ EDTA). The samples were resolved by electrophoresis through a $7 \mathrm{M}$ urea, $4 \%$ polyacrylamide gel, and the gels were dried and exposed on to Xray film for $24 \mathrm{~h}$.

mRNA stability. To measure the decay rate of RNA1 and RNA2, transformants of C600ams1 or C600 for pRJ5.5 (Fig. 1D) were grown in LB-ampicillin at $32{ }^{\circ} \mathrm{C}$ to late exponential phase $\left(\mathrm{OD}_{600} 0 \cdot 6\right)$. The cultures were split in halves and the incubation continued at either $32{ }^{\circ} \mathrm{C}$ or $43{ }^{\circ} \mathrm{C}$ for $40 \mathrm{~min}$. Rifampicin $\left(500 \mu \mathrm{g} \mathrm{ml}^{-1}\right)$ was added to stop further RNA initiation, and samples were drawn at different times (see Fig. 6B) to be processed for Northern blot assay as described above. The RNA1 and RNA2 bands were revealed by autoradiography of ${ }^{32} \mathrm{P}$-labelled probe $\mathrm{F}$ bound onto the transferred membranes and the amount of radioactivity estimated in a scintillation counter (Beckman LS6500). The percentage of RNA was calculated from the ratio between the radioactivity measured in an RNA band at a given time and the radioactivity in the band at zero time, after subtraction of background membrane radioactivity.
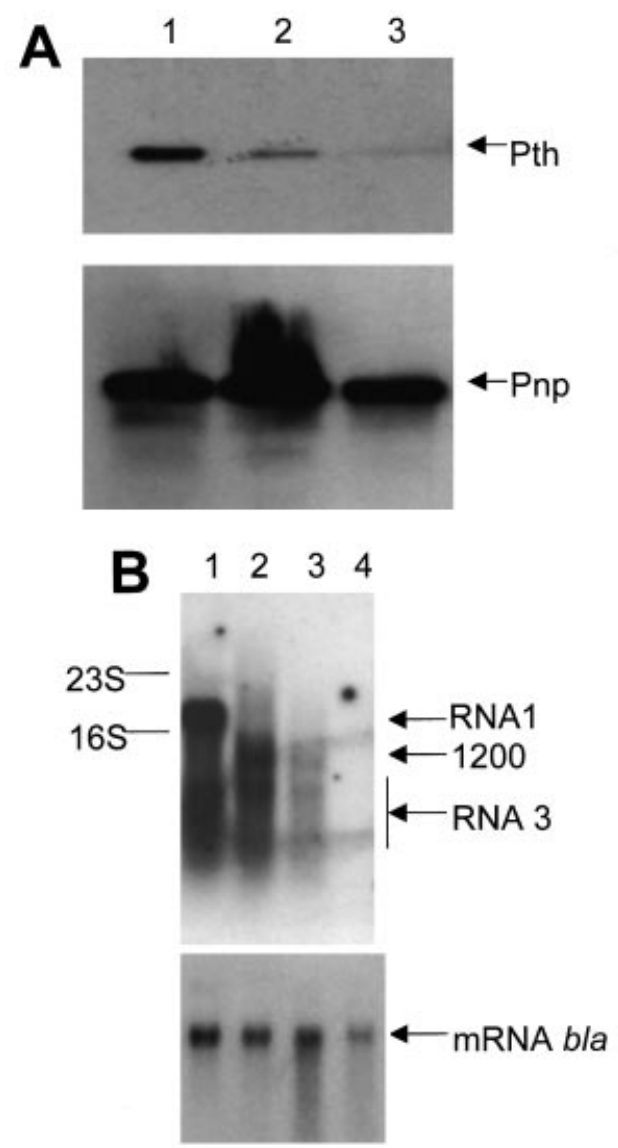

Fig. 5. Effect of the $y c h F$ and $y c h H$ deletions on pth expression. (A) Western blot assay of protein extracts obtained from cells transformed with pRJ5.5 (lane 1), pRJ1.0 (lane 2) and pRJ1.6 (lane 3) with anti-Pth (upper panel) and anti-Pnp (lower panel) rabbit antisera (see Methods). The Pth protein concentrations calculated from three independent experiments for each transformant were: pRJ5.5, $20 \pm 5.0 \mathrm{ng}$; pRJ1.0, $8.6 \pm 3.5 \mathrm{ng} ;$ pRJ1.6, $4.3 \pm 4.5 \mathrm{ng}$; per $\mu \mathrm{g}$ total protein. (B) Upper panel, Northern blot assay of the ychF transcripts from RNA preparations obtained from cells transformed with: pRJ5.5, lane 1; pRJ1.0, lane 2; pRJ1.6, lane 3; pRJ0.8, lane 4 revealed with ${ }^{32} \mathrm{P}$-labelled probe $\boldsymbol{P}$. The radioactive signal is directly comparable, as the four constructs carry the pth region complementary to the probe. Lower panel, Northern blot assay of bla transcripts from the gene carried in each of the constructs (see Methods).

Primer extension assays. About $10 \mu \mathrm{g}$ total RNA was assayed, essentially as described by Mateos et al. (1994). For experiments in Fig. 3(C), the same oligonucleotide, 5'-GCGCAAACGCTCTGCC-3', was used for the extension assay and for sequencing reactions. For experiments in Fig. 4(A), the oligonucleotide used was 5'-GCTTCAATACCGGC-3'. The oligonucleotides were labelled with $\left[\gamma^{-32} \mathrm{P}\right] \mathrm{ATP}$ by the phosphate-exchange reaction described above. A sequencing ladder was generated with pRJ5.5 as a template by using the AmpliCycle sequencing kit (Applied Biosystems). A $4 \mu \mathrm{l}$ sample of the primer extension or sequencing ladder reactions was resolved by electrophoresis through $7 \mathrm{M}$ urea, $8 \%$ polyacrylamide gel. The gel was then dried and exposed as indicated above.

Western blotting. The immunodetection assays in Fig. 5(A) 
were carried out as described elsewhere (Cruz-Vera et al., 2000). The samples were resolved through an SDS-polyacrylamide gel : $10 \%$ for polynucleotide phosphorylase (Pnp), or $15 \%$ for Pth. The antisera used were raised by immunization of rabbits with a purified preparation of Pth (Cruz-Vera et al., 2000) or Pnp protein (García-Mena et al., 1999).

\section{RESULTS}

\section{Transcripts that contain pth and ychF sequences}

Genes $p t h$ and $y c h F$ are contiguous and oriented in the same direction in the E. coli chromosome (Fig. 1B; Galindo et al., 1994; García-Villegas et al., 1991). We investigated the transcriptional relationships of these genes by Northern blot assays. The concentration of chromosome-directed transcripts from $p t h$ is undetectable by Northern blot due to their low concentration. Therefore, we used total RNA extracted from C600 cells transformed with pR J5.5 (Fig. 1D). pRJ5.5 is a derivative of pGEM-4, a vector which does not interfere with transcription initiated at promoters in the inserts. The RNA was revealed with in vitro-labelled ${ }^{32} \mathrm{P}-\mathrm{RNA}$ probes, complementary to the initial segment in $p$ th $(\mathbf{P})$ and in $y c h F(\mathbf{F})$ (Fig. 2). Construct pR J5.5, which directs Pth and Gtp1 proteins (data not shown), yielded two RNA populations revealed by probe $\mathbf{P}$ : one, a discrete band of $2000 \mathrm{nt}$ called RNA1, and the other, a smear of RNAs from 800 to 200 nt named RNA3 (Fig. 2, lane 1). Probe $\mathbf{F}$ also revealed two types of transcripts: again RNA1, the band of $2000 \mathrm{nt}$, and a more robust band of 1400 nt (Fig. 2, lane 2 RNA2). It is likely that (1) RNA1 is a bicistronic transcript that harbours both $p t h$ and $y c h F$ messages, (2) the heterogeneous RNA3 revealed by the probe $\mathbf{P}$ contains proximal $p$ th sequences of variable sizes and (3) RNA2, revealed only with the probe F, corresponds to $y c h F$ monocistronic transcripts of the predicted size (1400 nt).

\section{Transcriptional initiation of pth and $y c h H$}

The reported sequence between $y c h H$ and $p t h$ in the $E$. coli chromosome contains three $\sigma^{70}$-like promoter sequences (Fig. 3A; Hawley \& McClure, 1983; Wosten, $1998)$. One $\sigma^{70}$ promoter presumably controls initiation of $p t h$ transcripts and the other two promoters, oriented in the opposite direction, could initiate transcripts containing $y c h H$ sequences. To investigate the activity of these promoters, we looked for the predicted transcripts by nuclease S1-protection assays. Total RNA extracted from strain C600 transformed with pR J5.5 and $5^{\prime}$-end ${ }^{32} \mathrm{P}$-labelled DNA probes $\mathbf{a}$ and $\mathbf{b}$ were used (Fig. 1C; see Methods). Probe a, a 2.4 kb EcoRI-ApaLI fragment comprising $y c h H$, pth and most of $y c h F$, yielded four protected fragments, visualized as two strong and two weak bands (Fig. 3B, lane 2). However, probe b, $0.5 \mathrm{~kb}$ longer than a (Fig. 1C), yielded only one fragment, which migrated nearly as band IV revealed by probe a (Fig. 3B, lane 5). Using the nuclease S1protection assay, which is about 100 -fold more sensitive than Northern blot assay, similar fragments were observed with RNA extracted from untransformed cells (not shown). Therefore, the protecting transcripts were not initiated at vector promoters. These results show that the ends of the RNAs protected by fragments I, II and $750 \mathrm{nt}$ are located within the $0.5 \mathrm{~kb}$ segment between the ApaLI and ClaI sites (Fig. 1C). Fragment IV should be protected by a transcript divergent to the transcripts that protect fragments I, II (Fig. 1C) and should contain ychH sequences (Fig. 3A). The calculated sizes of the protected fragments revealed by probe a indicate that: (1) the faint signal of fragment I, above $1353 \mathrm{bp}$, is protected by RNA1 (Fig. 1A) the 5'-end of which is located between $p t h$ and $y c h H ;(2)$ the strong band, of about $1000 \mathrm{bp}$, of fragment II is protected with RNA2 (Fig. 1A), the $5^{\prime}$-end of which is located between pth and $y c h F$; and (3) the fragment of $750 \mathrm{nt}$, also a weak signal, corresponds to a transcript spanning from a site somewhere within $y c h F$ to the end of probe a.

\section{Start sites of pth transcripts}

To define the start sites of the $p t h$ transcripts, we determined their $5^{\prime}$-ends by primer extension on an RNA preparation of strain C600 transformed with pR J5.5 (see Methods and Fig. 3C). A unique signal was detected at the cytidine located seven bp downstream from the -10 box of the putative promoter for $p t h$ (Fig. $3 \mathrm{~A},+1)$. It is very likely that this signal corresponds to a transcriptional initiation site because: (1) in S1 protection assays, only one protected DNA fragment was visualized, implying that the primer extension signal was not due to an unspecific AMV reverse transcriptase drop-off (data not shown); and (2) the $5^{\prime}$-end cytidine was confirmed by primer extension on in vitro transcripts generated by RNA polymerase $\sigma^{70}$ (result not shown). These data strongly suggest that the identified Ppth promoter (Fig. 3C) indeed controls $p t h$ transcription.

\section{Transcriptional start for $y c h F$ transcripts}

Evidence for the existence of a transcriptional promoter, specific for $y c h F$, was derived from a plasmid construct that expressed protein Gtp1 even in the absence of a $p t h$ promoter region (data not shown). To investigate the presence of a transcriptional promoter in front of $y c h F$, we attempted to identify the $5^{\prime}$-end of the corresponding transcripts through primer extension experiments. The assay, again, was conducted on RNA prepared from cells transformed with pRJ5.5 (see Methods). Results showed that the strongest signal detected corresponded to the adenine located at $6 \mathrm{bp}$ downstream from a consensus -10 box of a putative promoter (Fig. 4A, s1, and Fig. 4B). Other minor signals were identified at one adenine (s2), at $16 \mathrm{bp}$, and two thymines, at 11 and $17 \mathrm{bp}$, downstream from the box (Fig. 4B). To find out which of these $5^{\prime}$-ends corresponded to $y c h F$ transcription initiation sites, we performed in vitro experiments using RNA polymerase $\sigma^{70}$ in the presence of $[\gamma$ $\left.{ }^{32} \mathrm{P}\right] \mathrm{ATP}$ or $\left[\gamma_{-}{ }^{32} \mathrm{P}\right] \mathrm{UTP}$. Results showed the incorporation only of adenine at the $5^{\prime}$-end of the transcripts. Primer extension assays of the in vitro transcripts 
revealed only the ends corresponding to the adenines in positions 6 and 16 (not shown). Taken together, these data show the presence of PychF specific for $y c h F$.

\section{3 -ends of transcripts containing ychF sequences}

We investigated the termination sites of the transcripts originated at P pth and PychF. Results in Fig. 3(B) had suggested that the $3^{\prime}$-ends of $y c h F$ transcripts were located within the ApaLI-ClaI DNA segment (Fig. 1B). To locate the $3^{\prime}$-ends of those transcripts precisely, we performed S1-nuclease protection using the ApaLI-ClaI DNA fragment ${ }^{32} \mathrm{P}$-labelled at the ApaLI end (see Fig. $1 \mathrm{C}$, probe c, and Methods). The RNA extracted from strain C600 transformed with pRJ5.5 yielded only one protected DNA fragment (Fig. 4C, lane 2). From this result and the fragment size, it seems that the $3^{\prime}$-end of the transcripts is unique and located about $50 \mathrm{nt}$ past the EcoRV site at coordinate 2.7 (Fig. 1B). The sequence of this region (Oshima et al., 1996) does not show any recognizable rho-independent transcription terminators (Lesnik et al., 2001). However, two pairs of inverted repeats were recognized beyond the $y c h \mathrm{~F}$ termination codon. In addition, we identified a short ORF of 21 codons that overlapped with the second inverted repeat (Fig. 4D).

\section{Effect of $y c h F$ sequences on Pth protein concentration}

The $p$ th transcript is found in two types of RNA : a long homogeneous bicistronic $p t h-y c h F$ message and a smear of transcripts from 200 to $800 \mathrm{nt}$ (Fig. 2). Since $p$ th ORF is $650 \mathrm{nt}$ long, the smear could result from 3 '-exonucleolytic degradation of longer $p t h$ transcripts. To investigate the efficiency of Pth expression from both types of transcripts, we compared the levels of Pth protein from pRJ5.5, which contains the complete $p t h-y c h F$ operon, and $\mathrm{pRJ} 1 \cdot 6$, which carries a deletion of most of the $y c h F$ $3^{\prime}$ region. Results showed that the concentration of Pth protein in extracts from cells transformed with pRJ5.5 was about fivefold higher than that in extracts from cells transformed with pRJ1.6 (Fig. 5A; compare lanes 1 and 3 , upper panel). This effect is specific to Pth, since the concentrations of Pnp, an unrelated protein, remained unchanged in both transformants (lower panel). Transexpression of $y c h F$ from an overproducing construct did not affect Pth concentration (result not shown). This implies that $y c h F$ sequences affect $p$ th expression in cis.

\section{Effect of $y c h F$ sequences on pth transcripts}

To investigate how the $y c h F$ region affected Pth levels, we tested the effect of $y c h F$ deletions on $p t h$ mRNA from pRJ1.6. We carried out Northern blot assays on RNA samples from C600 transformants using probe P. The results showed a $1200 \mathrm{nt} \mathrm{RNA}$ in $\mathrm{pRJ} 1 \cdot 6$, instead of the 2000 nt RNA1 observed with pRJ5.5, as expected from the $y c h F$ deletion (Fig. 5B, upper panel, compare lanes 3 and 1). Also visible in pRJ1.6 is the smear of partially degraded $p$ th message not present in the pRJ0.8 con- struct, carrying a $p$ th deletion (lane 4). A quantitative analysis of radioactive probe hybridized in lanes 1 and 3 showed that the $p t h$ transcripts from pRJ1.6 are just $20 \%$ of those from pRJ5.5. This calculation has taken into account variations in the mean copy number of plasmid constructs per cell, as it has been normalized to the levels of $\beta$-lactamase transcripts also encoded in the constructs (Fig. 5B, lower panel). As the constructs used carry the same original $p t h$ promoter, it was likely that the variations in $p$ th transcript concentrations in the transformants were due to the effect of distal $y c h F$ sequences on $p t h$ transcript stability. In fact, the half-life of the $p t h-y c h F$ complete pRJ5.5 transcripts was $2 \mathrm{~min}$ compared with less than 0.5 min for the pRJ1.6 transcripts (data not shown).

\section{Effect of RNase E on the expression of pth from the bicistronic transcript}

To investigate whether a particular endoribonuclease affected RNA1 and/or RNA2 stability, we used strains carrying a specific mutation in endoribonuclease $\mathrm{E}$ (RNase E) or in RNase III. A strain rnc105, a mutant affected in RNase III activity (Bardwell et al., 1989), carrying pRJ5.5 did not show any differences in concentration or in the $5^{\prime}$-ends of the $p t h$ transcripts relative to those in the wild-type strain. The mutation ams1 determines a thermosensitive RNase $\mathrm{E}$ at $43^{\circ} \mathrm{C}$ (McDowall et al., 1993). The half-lives of RNA1 and RNA2, as revealed by probe $\mathrm{F}$, increased dramatically at $43{ }^{\circ} \mathrm{C}$ in $\mathrm{C} 600$ ams 1 , relative to those at $32{ }^{\circ} \mathrm{C}$ (Fig. $6 \mathrm{~A}$, B). $p$ th sequences probed with $\mathbf{P}$ also showed an increased stability at $43^{\circ} \mathrm{C}$ (not shown). Interestingly, the stability of the transcripts from $\mathrm{pRJ} 1 \cdot 6$, carrying $p$ th (RNA3) but deleted for most of $y c h F$, was not affected (not shown). These results suggest that RNase $\mathrm{E}$ processes sequences of the $y c h F$ transcript, reducing $p t h$ mRNA stability. The low stability of pth mRNA is accompanied by a low Pth concentration at $32^{\circ} \mathrm{C}$ when RNaseE is active (Fig. 6C, upper panel). The concentration of Pnp was also higher at $43{ }^{\circ} \mathrm{C}$ than at $32{ }^{\circ} \mathrm{C}$ in the ams 1 strain, as expected from the fact that the $p n p$ messenger is processed by RNase E (Hajnsdorf et al., 1994). The protein concentrations at $32^{\circ} \mathrm{C}$ versus $43^{\circ} \mathrm{C}$ remained constant for both Pth and Pnp in the wild-type strain (Fig. 6, lower panel).

\section{Effect of the PychH region on pth expression}

We inquired whether the presence of the $y c h H$ region affected pth expression. The levels of Pth protein expressed from two constructs and accumulated in the cells were compared. One of the constructs, pRJ1·0, harbours the DdeI-EcoRV insert comprising $p t h$ and the initial sequences of $y c h F$. The other, pRJ1.6, carries a longer segment from site EcoRI before $y c h \mathrm{H}$ to the same EcoRV site in pRJ1.0 (Fig. 1D). The additional $200 \mathrm{bp}$ segment in pRJ1.0 upstream of Ppth includes the putative $y c h H$ promoters (Fig. 3A). The results of a Western blot assay (Fig. 5A upper panel, lanes 2 and 3) showed that the levels of Pth accumulated in trans- 


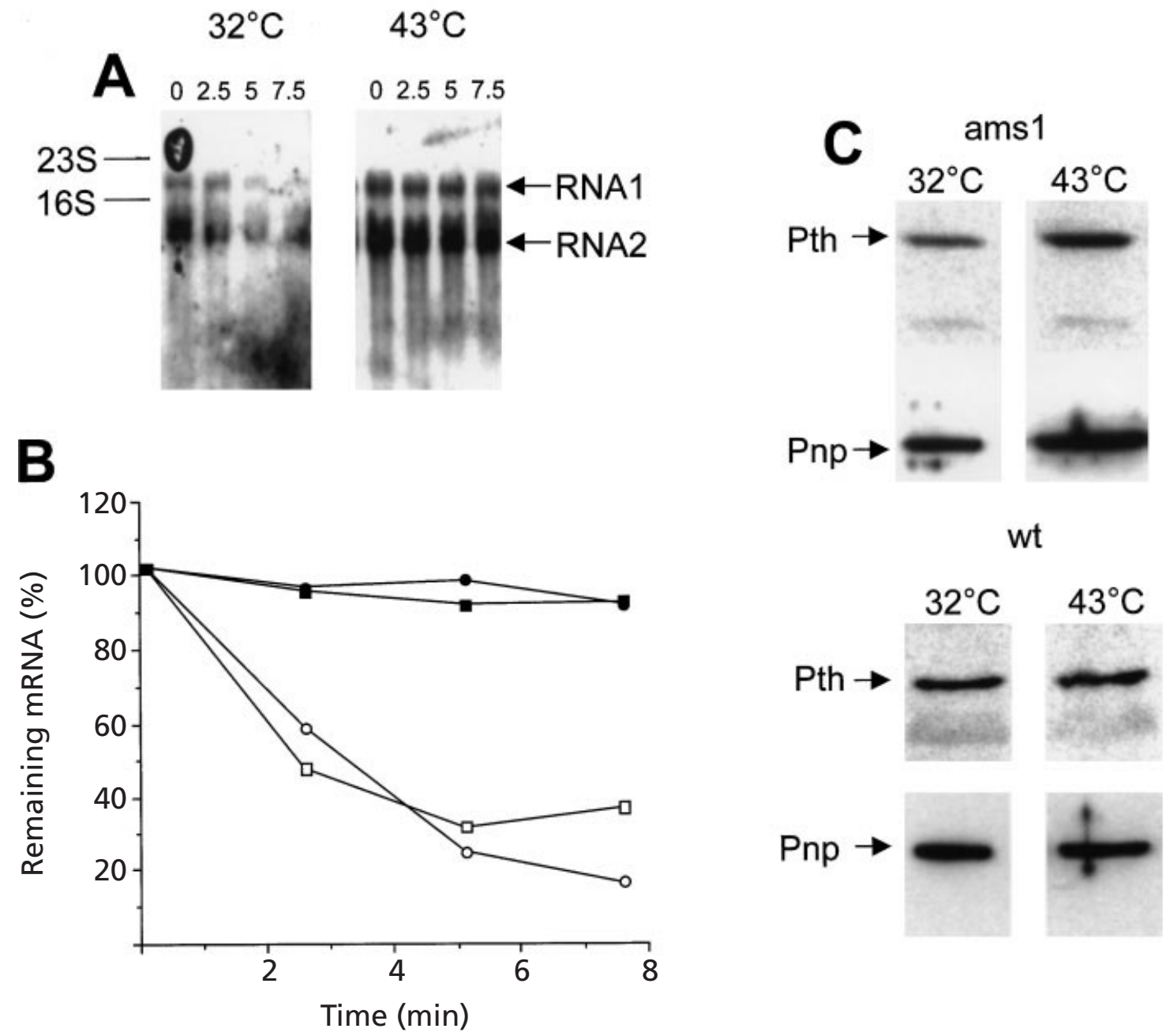

Fig. 6. Expression of $p$ th from the pth-ychF transcripts in the absence of endoribonuclease $E$ activity. (A) Samples of C600ams1, a mutant thermosensitive for RNase E activity, transformed with pRJ5.5 and growing at either 32 or $43{ }^{\circ} \mathrm{C}$ were drawn at the indicated times after the inhibition of RNA synthesis with rifampicin. RNA1 and RNA2 were revealed by Northern blotting with ${ }^{32}$ P-labelled probe F (Fig. 1C; see Methods). (B) Time course of RNA decay in (A) measured as a percentage of the radioactive counts of labelled probe bound. $O$, RNA1 at $32{ }^{\circ} \mathrm{C}$; 9 , RNA1 at $43{ }^{\circ} \mathrm{C}$; $\square$, RNA2 at $32{ }^{\circ} \mathrm{C}$; - RNA2 at $43^{\circ} \mathrm{C}$. (C) Western blot assays for Pth and Pnp antigens in C600 (wt) and C600ams1 (ams1) after 40 min incubation at the indicated temperatures.

formants for $\mathrm{pRJ} 1 \cdot 0$ are, at least, twice those for $\mathrm{pRJ} 1 \cdot 6$. This difference in Pth protein concentration is paralleled by the $p t h$ transcript levels (Fig. 5B upper panel, compare lanes 2 and 3). Since the stability of the $p$ th transcripts from both pRJ1.0 and pRJ1.6 is the same, and the $y c h H$ expression from a plasmid did not affect Pth expression (data not shown), we conclude that $y c h H-p t h$ intercistronic sequences affect $p$ th transcription capacity. These sequences may be the putative $y c h$ promoters (Fig. 3A) or part of the RNA polymerase binding site for Ppth (Nickerson \& Achberger, 1995).

\section{DISCUSSION}

The expression of $p t h$ in E. coli remains tightly controlled under different conditions. Except for a mutation in rne (the gene encoding RNase E), and deletions of the regions flanking $p t h$ described here, we do not know of any other growth conditions or mutations outside of $p$ th that affect Pth protein levels. Changes in the medium composition, temperature of incubation and age of the culture did not affect Pth protein levels (data not shown). A mutation affecting Pth protein stability, $p t h(\mathrm{Ts})$, reduced the levels of the mutant enzyme at non-permissive temperatures, but there is no evidence that Pth is autoregulated (Cruz-Vera et al., 2000; García-Villegas et al., 1991).

The messages of $p t h$ and the 3 '-proximal gene, $y c h F$, are found as either bicistronic or monocistronic transcripts (Figs 1 and 2). The $p t h$-only transcripts are a smear of RNA-containing proximal $p t h$ sequences as if they were products of exonucleolytic decay (Figs 2 and 5B). However, we do not know whether the decay substrates 
are terminated $p t h$ monocistronic transcripts or processed bicistronic messages. If the latter case is correct, processing is not performed by RNase E (see below). It is likely that all $p t h$-containing transcripts originate from $\mathrm{P} p t h$, the only promoter identified upstream from the pth initiation codon (Fig. 3C; García-Villegas et al., 1991). The $y c h F$-only transcript is an abundant message initiated from a previously unidentified promoter, PychF, located between the pth and $y c h F$ ORFs.

The complete $p t h-y c h F$ bicistronic messenger is an efficient source for Pth accumulation; however, in the absence of distal $y c h F$ sequences, the $p t h$ messenger generates scant Pth protein levels (Fig. 5A). This result indicates that the $y c h F$ message stabilizes pth mRNA (Fig. 5B). The effect is in cis, as trans expression of $y c h F$ did not affect Pth protein accumulation (not shown). Apparently, there is no evolutionary advantage to keep the $p t h-y c h F$ pair together in bacterial chromosomes. The gene sequence $y c h H-p t h-y c h F$ observed in E. coli is typical of enterobacteria (McClelland et al., 2001; Parkhill et al., 2001). Other sequenced genomes such as Haemophilus (Fleischmann et al., 1995), Pseudomonas (Stover et al., 2000) and Mesorhizobium (GenBank: XL465) maintain the pair $p t h-y c h F$, whereas the rest of the sequenced bacterial genomes keep pth-, ychHand $y c h F$-homologous genes dispersed in different regions.

In a thermosensitive RNase $\mathrm{E}$ mutant, incubated at a non-permissive temperature, the mono- and bicistronic transcripts containing $y c h F$ (RNA1 and RNA2) are stabilized, but the heterogeneous $p t h$ transcripts are unaffected (RNA3, data not shown). We interpret this result to mean that at least one RNase E processing site is located within $y c h F$. The site may be in the transcript beyond ( $3^{\prime}$ to) the EcoRV site (coordinate 1·6, Fig. 1B) because the $5^{\prime}$-ends previous to the EcoRV site are the same in the presence or absence of RNase E activity (not shown). Endonucleolytic cleavage of mRNA is usually followed by $3^{\prime} \rightarrow 5^{\prime}$ exonucleolytic degradation (Higgins et al., 1993). Thus, RNase E activity may co-ordinately regulate the expression of both $p t h$ and $y c h F$ from the bicistronic transcript. Negative regulation by RNase E processing of ribonuclease messengers has been described for pnp (Hajnsdorf et al., 1994), rnb (Zilhao et al., 1995) and rne (Jain \& Belasco, 1995).

The in vivo concentration of the $y c h F$-only transcript is much higher than that of $p t h-y c h F$ (Fig. 2). These concentrations probably represent the transcription initiation frequencies at $\mathrm{P} y c h F$ and $\mathrm{P} p$ th because both transcripts are equally stable (Fig. 6A). This notion was reinforced by in vitro $\sigma^{70}$ RNA polymerase transcription; PychF is a stronger promoter than $\mathrm{P} p t h$ (not presented). Also, the degree of identity to the -10 and -35 consensus promoter boxes and the base composition of the spacer between boxes suggest that PychF may be a better promoter than Ppth (Hawley \& McClure, 1983). Although the spacer in Ppth corresponds to the consensus $17 \mathrm{bp}$, it includes $10 \mathrm{G}$ : $\mathrm{C}$ pairs that could reduce the transcriptional efficiency of the promoter (Auble \& deHaseth, 1988). In contrast, PychF features an atypical $24 \mathrm{bp}$ spacer but contains $5 \mathrm{bp}$ inverted repeats flanking a thymine tract (Fig. 4B), a sequence described for the promoter Pm of phage Mu. During complex formation of Pm DNA and RNA polymerase, a distortion occurs at the spacer allowing DNA strand separation at the thymine tract. This event favours the transition from a closed to an open complex and the initiation of transcription (Artsimovitch et al., 1996).

The $y c h H$ transcript probably originated from either of the two promoters identified by sequence in the $y c h H-$ $p t h$ intergenic region and oriented divergently from $\mathrm{P} p t h$ (Fig. 3A, B). Deletion of a DNA segment containing the $y c h H$ promoters in pRJ1.0 results in a stronger expression of $p t h$ mRNA and Pth protein (Figs 5A, B). Therefore, these promoters, or other element(s) in the intergenic sequence, may be inhibitory for $p t h$ expression.

\section{ACKNOWLEDGEMENTS}

We thank J. Plumbridge and F. De la Vega for generously sharing their preliminary results with us, for helpful comments on the manuscript and for the cya strain, and Jaime García Mena for the anti-PNPase antiserum. This work was supported by grants awarded to G. G. from the Consejo Nacional de Ciencia y Tecnología (CONACyT, Mexico), Consejo del Sistema Nacional de Educación Tecnológica (COSNET, Mexico) and the Howard Hughes Medical Institute. CONACyT no. 028 and COSNET awarded doctoral loanfellowships to L.R.C.V.

\section{REFERENCES}

Aiba, H., Adhya, S. \& de Crombrugghe, B. (1981). Evidence for two functional gal promoters in intact Escherichia coli cells. J Biol Chem 256, 11905-11910.

Artsimovitch, I., Kahmeyer-Gabbe, M. \& Howe, M. M. (1996). Distortion in the spacer region of Pm during activation of middle transcription of phage Mu. Proc Natl Acad Sci USA 93, 9408-9413.

Atherly, A. G. \& Menninger, J. R. (1972). Mutant E. coli strain with temperature sensitive peptidyl-transfer RNA hydrolase. Nature 240, 245-246.

Auble, D. T. \& deHaseth, P. L. (1988). Promoter recognition by Escherichia coli RNA polymerase. Influence of DNA structure in the spacer separating the -10 and -35 regions. J Mol Biol 202, 471-482.

Bardwell, J. C., Régnier, P., Chen, S. M., Nakamura, Y., GrunbergManago, M. \& Court, D. L. (1989). Autoregulation of RNase III operon by mRNA processing. EMBO J 8, 3401-3407.

Cruz-Vera, L. R., Toledo, I., Hernández-Sánchez, J. \& Guarneros, G. (2000). Molecular basis for the temperature sensivity of Escherichia coli pth(Ts). J Bacteriol 182, 1523-1528.

De la Vega, F. M., Galindo, J. M., Gold, I. G. \& Guarneros, G. (1996). Microbial genes homologous to the peptidyl-tRNA hydrolase-encoding gene of Escherichia coli. Gene 169, 97-100.

Dinçbas, V., Heurgué-Hamard, V., Buckingham, R. H., Karimi, R. \& Ehrenberg, M. (1999). Shutdown in protein synthesis due to the expression of mini-genes in bacteria. J Mol Biol 291, 745-759.

Dutka, S., Meinnel, T., Lazennec, C., Mechulam, Y. \& Blanquet, S. (1993). Role of the 1-72 base pair in tRNAs for the activity of 
Escherichia coli peptidyl-tRNA hydrolase. Nucleic Acids Res 21, 4025-4030.

Fleischmann, R. D., Adams, M. D., White, O. \& 37 other authors (1995). Whole-genome random sequencing and assembly of Haemophilus influenzae Rd. Science 269, 496-512.

Fromant, M., Plateau, P., Schmitt, E., Mechulam, Y. \& Blanquet, S. (1999). Receptor site for the $5^{\prime}$-phosphate of elongator tRNAs governs substrate selection by peptidyl-tRNA hydrolase. Biochemistry 38, 4982-4987.

Galindo, J. M., Guarneros, G. \& De La Vega, F. M. (1994). Open reading frames flanking the peptidyl-tRNA hydrolase-encoding gene of Escherichia coli. Gene 151, 153-156.

García-Mena, J., Das, A., Sánchez-Trujillo, A., Portier, C. \& Montañez, C. (1999). A novel mutation in the KH domain of polynucleotide phosphorylase affects autoregulation and mRNA decay in Escherichia coli. Mol Microbiol 33, 235-248.

García-Villegas, R., De La Vega, F. M., Galindo, J. M., Segura, M., Buckingham, R. H. \& Guarneros, G. (1991). Peptidyl-tRNA hydrolase is involved in $\lambda$ inhibition of host protein synthesis. EMBO J 10, 3549-3555.

Guzmán, G. \& Guarneros, G. (1989). Phage genetic sites involved in lambda growth inhibition by Escherichia coli rap mutants. Genetics 21, 401-409.

Hajnsdorf, E., Carpousis, A. J. \& Régnier, P. (1994). Nucleolytic inactivation and degradation of RNAse III processed pnp message encoding polynucleotide phosphorylase of Escherichia coli. J Mol Biol 239, 439-454.

Hawley, D. K. \& McClure, W. R. (1983). Compilation and analysis of Escherichia coli promoter DNA sequences. Nucleic Acids Res 11, 2237-2255.

Hernández, J., Ontiveros, C., Valadez, J. G., Buckingham, R. H. \& Guarneros, G. (1997). Regulation of protein synthesis by minigene expression. Biochimie 79, 527-531.

Hernández-Sánchez, J., Valadez, J. G., Vega-Herrera, J., Ontiveros, C. \& Guarneros, G. (1998). Lambda bar minigene-mediated inhibition of protein synthesis involves accumulation of peptidyltRNA and starvation for tRNA. EMBO J 17, 3758-3765.

Heurgué-Hamard, V., Karimi, R., Mora, L., MacDougall, J., Leboeuf, C., Grentzmann, G., Ehrenberg, M. \& Buckingham, R. H. (1998). Ribosome release factor RF4 and termination factor RF3 are involved in dissociation of peptidyl-tRNA from the ribosome. EMBO J 17, 808-816.

Heurgué-Hamard, V., Dinçbas, V., Buckingham, R. H. \& Ehrenberg, M. (2000). Origins of minigene-dependent growth inhibition in bacterial cells. EMBO J 19, 2701-2709.

Higgins, C. F., Causton, H. C., Dance, G. S. C. \& Mudd, H. A. (1993). RNA degradation. In Control of Messenger RNA Stability, pp. 13-30. Edited by J. Belasco \& G. Brawerman. San Diego, CA: Academic Press.

Jain, C. \& Belasco, J. G. (1995). RNase E autoregulates its synthesis by controlling the degradation rate of its own mRNA in Escherichia coli: unusual sensitivity of the rne transcript to RNase E activity. Genes Dev 9, 84-96.

Kohara, Y., Akiyama, K. \& Isono, K. (1987). The physical map of the whole E. coli chromosome; application of a new strategy for rapid analysis and sorting of large genomic library. Cell 50, 495-508.

Lesnik, E. A., Sampath, R., Levene, H. B., Henderson, T. J., McNeil, J. A. \& Ecker, D. J. (2001). Prediction of rho-independent tran- scriptional terminators in Escherichia coli. Nucleic Acids Res 29, 3583-3594.

Manson, P. J. \& Williams, J. G. (1985). Hybridisation in the analysis of recombination DNA. In Nucleic Acid Hybridisation, a Practical Approach, pp. 213-276. Edited by B. D. Hames \& S. J. Higgins. Oxford: IRL Press.

Mateos, L. M., Pisabarro, A., Pátek, M., Malumbres, M., Guerrero, C., Eikmanns, B. J., Sahm, H. \& Martín, J. F. (1994). Transcriptional analysis and regulatory signals of the hom-thrB cluster of Brevibacterium lactofermentum. J Bacteriol 176, 7362-7371.

McClelland, M., Sanderson, K. E., Spieth, J.\& 23 other authors (2001). Complete genome sequence of Salmonella enterica serovar typhimurium LT2. Nature 413, 852-856.

McDowall, K. J., Hernández, R. G., Lin-Chao, S. \& Cohen, S. N. (1993). The ams-1 and rne-3071 temperature-sensitive mutations in the ams gene are in close proximity to each other and cause substitutions within a domain that resembles a product of the Escherichia coli mre locus. J Bacteriol 175, 4245-4249.

Menez, J., Heurgué-Hamard, V. \& Buckingham, R. H. (2000). Sequestration of specific tRNA species cognate to the last sense codon of an overproduced gratuitous protein. Nucleic Acids Res $28,4725-4732$.

Nickerson, C. A. \& Achberger, E. C. (1995). Role of curved DNA in binding of Escherichia coli RNA polymerase to promoters. J Bacteriol 177, 5756-5761.

Ontiveros, C., Valadez, J. G., Hernández, J. \& Guarneros, G. (1997). Inhibition of Escherichia coli protein synthesis by abortive translation of phage lambda minigenes. J Mol Biol 269, 167-175.

Oshima, T., Aiba, H., Baba, T. \& 52 other authors (1996). A 718$\mathrm{kb}$ DNA sequence of the Escherichia coli K-12 genome corresponding to the $12 \cdot 7-28.0 \mathrm{~min}$ region on the linkage map. DNA Res 3, 137-155.

Parkhill, J., Wren, B. W., Thomson, N. R. \& 38 other authors (2001). Genome sequence of Yersinia pestis, the causative agent of plague. Nature 413, 469-470.

Régnier, P. \& Portier, C. (1986). Initiation, attenuation and RNase III processing of transcripts from the Escherichia coli operon encoding ribosomal protein S15 and polynucleotide phosphorylase. J Mol Biol 187, 23-32.

Rudd, K. E. (1992). Alignment of E. coli DNA sequences to a revised, integrated genomic restriction map. In A Short Course in Bacterial Genetics: a Laboratory Manual and Handbook for E. coli and Related Bacteria, pp. 2.3-2.43. Edited by J. H. Miller. Cold Spring Harbor, NY: Cold Spring Harbor Laboratory.

Schmitt, E., Mechulam, Y., Fromant, M., Plateau, P. \& Blanquet, S. (1997). Crystal structure at $1.2 \AA$ resolution and active site mapping of Escherichia coli peptidyl-tRNA hydrolase. EMBO J 16, 4760-4769.

Stover, C. K., Pham, X. Q., Erwin, A. L. \& 28 other authors (2000). Complete genome sequence of Pseudomonas aeruginosa PAO1, an opportunistic pathogen. Nature 406, 959-964.

Wosten, M. M. (1998). Eubacterial sigma-factors. FEMS Microbiol Rev 22, 127-150.

Zilhao, R., Régnier, P. \& Arraiano, C. M. (1995). The role of endonucleases in the expression of ribonuclease II in Escherichia coli. FEMS Microbiol Lett 130, 237-244.

Received 31 May 2002; revised 18 July 2002; accepted 24 July 2002. 